\title{
Emergência dos equipamentos coletivos: Estado do progresso dos trabalhos ${ }^{1}$
}

\section{Philippe Chevalier}

\section{Tradução de Marcos Nalli e Tiaraju Dal Pozzo Pez}

\section{Michel Foucault e o CERFI: um estranho "inédito"}

Fazendo o inventário dos arquivos de seu colega falecido do departamento de Filosofia de Paris 8, Kyril Ryik, Alain Brossat se deparou com um texto datilografado e mimeografado intitulado "Emergência dos equipamentos coletivos: Estado do progresso dos trabalhos", com a menção manuscrita lacônica "Foucault, julho de 1974". Este texto não está nos Dits et Écrits, posto que evidentemente ele jamais foi publicado. Ele não se encontra também - sob reserva de inventário exaustivo - nos arquivos Foucault depositados na BnF.

O texto datilografado se apresenta como esboço, corrigido e anotado à mão - provavelmente de uma mesma mão, mas sem certeza -, de um relatório intermediário cujo destinatário é o demandante de uma pesquisa contratada. À leitura do texto, cujas referências pitorescas não enganam por muito tempo, uma evidência se impõe: o texto é certamente de Foucault, a tal ponto que se tem a impressão momentânea de ler um resumo de passagens de Surveiller et Punir, que vem à lume sete meses mais tarde (fevereiro de 1975). No que se refere às notas

1 Publicado originalmente em Ici et Ailleurs <https:/ici-et-ailleurs.org/contributions/politique-et-subjectivation/article/ emergence-des-equipements>. Acesso em: 28 out. 2018.

Optamos por preservar as referenciações em notas de rodapé como está no original (N. T.). 
bibliográficas, as notas de pé de página se seguem e se assemelham: o Moyens de rendre les hôpitaux utiles [Meios de tornar os hospitais úteis], de 1787 - citado desde Naissance de la Clinique -, a Instruction méthodique pour l'école paroissiale [Instrução metódica para a escola paroquial], de 1669, as Règlements pour les écoles de la ville de Lyon [Regras para as escolas da cidade de Lyon], de 1716, o Registre des délibérations de l'Hôtel-Dieu [Registro das deliberações do Hôtel-Dieu], de 1620, Camille de Rochemonteix, Jean-Baptiste de la Salle: todos se encontram citados nos capítulos "Os corpos dóceis" e "Os meios para um bom adestramento" da terceira parte de Surveiller et Punir. A coisa é bizarra: a parte de Surveiller et Punir dedicada ao nascimento do controle individual tivera por formato primeiro um relatório administrativo?

Apenas encontramos, nos documentos desta época publicados ou acessíveis on-line, uma única menção ao título "Emergência dos equipamentos coletivos". Um documento da Maison des Sciences de $L^{\prime} H_{0 m m e}$ Boulevard Raspail²- indica com efeito que o Centre d'Études, de Recherches et de Formation Institutionnelles [Centro de Estudos, de Pesquisa e de Formação institucionais] (CERFI), de Félix Guattari, era titular desde junho de 1973 de um contrato sob este título autorizado pelo Serviço de Questões Econômicas e Internacionais (SAEI) do Ministério do equipamento. A assinatura no contrato era então de Gilles Deleuze pelo CERFI.

Malgrado a pequena diferença entre os títulos, esta pesquisa parece apenas fazer uma "Genealogia dos equipamentos coletivos", trabalho coletivo dirigido por Foucault no quadro de um contrato engajando o CERFI, a Delegação Geral para a Pesquisa Científica e Técnica (DGRST) e o SAEI ${ }^{3}$. Este trabalho se compõe de uma primeira parte dedicada à escola primária e de uma segunda dedicada aos equipamentos

2 " m.s.h. informations », p. 5 : « organismes de financement de la recherche » (http://nabu.fmsh.fr/file/misc/imagesFR075FMSH_000000038/FMSH_PB1063_2D2_000.pdf, consultado em 20 de outubro de 2018).

A Maison des Sciences de l'Homme (MSH) é um núcleo de pesquisa e ensino ligada à École des Hautes Études en Sciences Sociales (EHESS), localizada na Boulevard Raspail, Paris - França (N. T.).

3 SAEl et DGRST são indistintamente citados nas menções oficiais que acompanham as publicações deste trabalho coletivo, sempre em referência à mesma concessão no. 73-01-503. Em um artigo dedicado à colaboração de Foucault como 0 CERFI, Liane Mozère indica que o filósofo era"fiador do terceiro contrato de pesquisa de importância [do CERFI] sobre a Genealogia dos equipamentos coletivos para 0 orçamento do Ministério do Equipamento" (Liane Mozère, "Foucault et le CERFI :

Rev. Filos., Aurora, Curitiba, v. 31, n. 52, p. 367-389, jan./abr. 2019 
sanitários (consistindo de três seções: a instituição hospitalar no século XVIII, os equipamentos psiquiátricos no século XIX, e a história da psiquiatria de setor $)^{4}$. Constatação saborosa: os serviços governamentais não jogaram um magro papel nas reflexões sobre o nascimento da sociedade disciplinar. Parte desta pesquisa será considerada na obra coletiva Les Machines à Guérir. Aux origines de l'hôpital moderne [As máquinas de curar. Nas origens do hospital moderno] (Paris, Institut de l'environnement, 1976) $)^{5}$.

O presente texto estaria então no projeto de relatório trimestral redigido por Foucault para esta pesquisa contratada pelo CERFI. Nada de surpreendente: desde 1972, Foucault é próximo ao coletivo de Guattari, participa das reuniões locais, presta-lhe seu apoio amigável, isto é, sua caução intelectual. O número de dezembro de 1973 da revista do coletivo Recherches, que trata precisamente sobre "Os equipamentos do poder" ${ }^{\prime \prime}$, contém duas entrevistas em que o filósofo participa: "Primeiras discussões, primeiros balbucios: a cidade é uma força produtiva ou de antiprodução?" (Dits et Écrits, t. II, p. 447-451), com Guattari e com o economista François Fourquet, e "Arrancados por intervenções enérgicas de nossa permanência eufórica na história

instantanés et actualité », Le Portique [http://journals.openedition.org/leportique/642], 13-14 | 2004, disponível on-line 'em 15 de junho de 2007, consultado em 13 de outubro de 2018).

4 Essas duas partes de uma mesma pesquisa são claramente mencionadas em duas publicações do CERFI que lhe prestam contas: Anne Querrien, Généalogie des équipements collectifs, Les équipements de normalisation, Lécole primaire, Paris, CERFI, Impr. Copédith, 1975; Michel Foucault (dir.), Généalogie des équipements de normalisation, Les équipements sanitaires, Paris, CERFI, Impr. Copédith, 1976. Parece, ao contrário, pertencer a uma outra pesquisa, mesmo que ela tenha sido publicada sob o mesmo título « Généalogie des équipements collectifs »: François Fourquet, Histoire des services collectifs dans la comptabilité nationale, Paris, CERFI, Impr. Copédith, 1976.

5 [Nota corrigida em 09/02/2019] Um capítulo do livro e a própria introdução de Foucault já se encontra em FOUCAULT, Michel (dir.), Généalogie des équipements de normalisation, op. cit., mesmo se tratando de um volume sensivelmente diferente. A reedição de Machines à guérir em 1979 (Bruxelles, Pierre Mardaga) Ihe acrescenta os resultados de outra pesquisa, dirigida pelo arquiteto e urbanista Bruno Fortier: « La politique de l'espace parisien à la fin de l'Ancien Régime », seguido de um contrato ao Comité de la recherche et du développement en architecture [Comitê da Pesquisa e do Desenvolvimento em Arquitetura ] (CORDA)/DGRST. Segundo Daniel Defert, Fortier, então responsável pelo CREDA, criado em janeiro de 1973, participa do seminário de Foucault no Collège de France durante 0 ano de 1973-1974, 0 qual versava, entre outros, sobre "I'histoire de l'institution et de l'architecture hospitalières au XVIIle siècle » (Dits et Écrits, n 143 ; Daniel Defert, "Hétérotopie : tribulation d'un concept entre Venise, Berlin et Los Angeles », dans Michel Foucault, Le corps utopique, les hétérotopies, Paris, Nouvelles éditions lignes, 2009, p. 49).

6 Généalogie du capital, t. 1 : «Les équipements du pouvoir», Recherches, décembre 1973. 
pomos 'categorias lógicas' a trabalhar" (Dits et Écrits, t. II, p. 452-4567), com Deleuze e Guattari.

O conteúdo deste inédito poderá desapontar: o "estado de avanço dos trabalhos", redigido por Foucault para o CERFI, parece ser o estado de avanço de sua própria redação de Surveiller et Punir, livro que estará pronto no mês seguinte, em agosto de 1974. Uma primeira hipótese, Foucault seria aqui apenas um representante com o fito de ajudar os jovens pesquisadores do CERFI submetidos às circunstâncias da pesquisa contratada, que era então o único quadro de financiamento do coletivo. Tal era também o papel de Deleuze e de Foucault: obter para os pesquisadores precários os contratos necessários, reciclar trabalhos pessoais e "relatar" em seguida ao financiador o que era necessário quando o fora. Uma segunda hipótese, seria preciso supor que a redação de Surveiller et Punir teve inspirações mais coletivas do que parece; conviria então liberar o livro de sua função-autor para encontrar nele a efervescência de um grupo, a transversalidade de suas práticas, a fluidez de seus conceitos. Uma das publicações do CERFI sobre a presente pesquisa compreende alhures um capítulo inteiro consagrado a alguns dos temas apresentados por Foucault em seu relatório de julho de $1974^{8}$.

O interesse deste texto é, por um lado, o de lembrar um fato pouco conhecido de nossa história intelectual: o lugar do CERFI nos trabalhos de Foucault durante os anos 1972-1975. Guattari e o CERFI não são mencionados na biografia clássica de Didier Éribon (Michel Foucault. Flammarion, 1980, 2011) e Bernard Harcourt não diz nada em sua edição de Surveiller et Punir na Bibliothèque de la Pléiade (Euvres, t. 2, Gallimard, 2015). Na história tal como contada, a gênese do grande livro sobre a prisão segue sempre uma linha reta e estritamente foucaultiana, esta que alojaria de um lado um campo teórico (os cursos no Collège de France de 1971-1972 até 1973-1974) e do outro um campo militante (o GIP), desenvolvimento supostamente ingênuo que nada

FOUCAULT, Michel. Ditos e Escritos, v. IV: Estratégia, poder-saber. Rio de Janeiro: Forense, 2006. p. $81-86$ (N. T.).

8 Sobre a vigilância e a escrita médica no contexto hospitalar, cf. Michel Foucault (dir.), Généalogie des équipements de normalisation, op. cit., chapitre 2: « Le fonctionnement de l'hôpital », p. 25-39. 
diz de outros coletivos de pesquisa, outras tradições de pensamento e sobretudo outros interlocutores: arquitetos, economistas, sociólogos e urbanistas. À exceção de um artigo de Daniel Defert ${ }^{9}$ e dos trabalhos de Stuart Elden ${ }^{10}$, raramente Surveiller et Punir é visto por uma reflexão sobre as cidades, os territórios e os "equipamentos do capital". Esperamos que esta publicação reabra o dossier Foucault-DeleuzeGuattari e suscite novas pesquisas, tão livres e coletivas quanto aquelas dos anos libidinais do CERFI. Não se trata tanto, aqui, de exumar um inédito que teria os contornos de uma pérola rara e única - não é seguramente nem uma coisa e nem outra - senão de suscitar um trabalho coletivo em torno de algumas palavras-chaves: "espaço", "território", "arquitetura", "equipamentos", "instituição".

Esta edição on-line foi possível graças aos trabalhos meticulosos de Cédric Cagnat, Orgest Azizaj, Sandrine Amy e Alain Brossat, para a Associação "Ici et Ailleurs". Eles se dedicaram a permanecer o mais próximo possível do texto datilografado, corrigindo apenas alguns erros de pontuação e de ortografia evidentes (em particular sobre dois nomes próprios). As referências bibliográficas foram todas homogeneizadas em sua forma e deixados em seu conteúdo aproximativo ou lacunar. Os sublinhados, de origem incerta, não foram, no entanto, mantidos.

Enfim, agradecemos calorosamente Henri-Paul Fruchaud, sobrinho de Michel Foucault, de ter dado sua concordância a esta publicação.

\section{Emergência dos equipamentos coletivos}

\section{Estado de progresso dos trabalhos}

O trabalho do último trimestre foi consagrado ao estudo de um ponto que estava indicado no relatório precedente: os sistemas

9 Daniel Defert, « Hétérotopie : tribulation d'un concept entre Venise, Berlin et Los Angeles », op. cit., p. 50.

10 Stuart Elden, Foucault's Last Decade, Cambridge, Polity Press, 2016 ; Foucault : The Birth of Power, Cambridge, Polity Press, 2017. 
documentais em um certo número de instituições como a escola, o exército, o hospital e este, no curso dos séculos XVII e XVIII. Este conjunto foi escolhido por um certo número de razões:

1) Vê-se a transferência de grandes procedimentos de registro fiscal, econômico e judiciário a um domínio novo, aquele dos indivíduos e de sua conduta.

2) Vê-se formar através dessas instituições e desses procedimentos um tipo de poder absolutamente específico cujos controles políticos ou religiosos da época precedente não tinham exemplos a dar.

3) Constituem-se aí mecanismos de controle fins e detalhados que permitiram a formação e o acúmulo de todo um saber sobre os indivíduos.

Não há disciplina sem um arquivo consistente, minucioso, no nível dos corpos e dos dias, sem procedimentos documentais que permitam integrar dados minúsculos, sem circuitos que os centralizem e os distribuam. As disciplinas que colocam os indivíduos em um campo de vigilância os situam igualmente em uma rede de escrita; elas os engajam em todo um volume de documentos que os capta e fixa. As instituições disciplinares foram desde muito cedo os lugares de registro intenso e acúmulo documentais. Como toda administração, sem dúvida, como aparelho judiciário ou fiscal, mas com problemas específicos e com técnicas que lhes são apropriadas.

Trata-se de estabelecer para cada indivíduo uma identidade característica, que pode ser reconhecida, forçada, inamovível; de se dar sobre eles singularmente mas em sua multiplicidade, uma apreensão que seja menos abstrata que os documentos fiscais, os registros de batismo ou os atos judiciários. É preciso fazer entrar nos corpos as atitudes, os comportamentos, as condutas, em um sistema de localização e classificação; problema então de taxinomia, não a tal ponto de fazer aparecer espécies e sim para reconhecer os traços singulares de um indivíduo, o que o torna simultaneamente insubstituível e utilizável. Em lugar de especificar como não importa qual ser natural que se reconhece, identificá-lo como um indivíduo sobre o qual se exerce um poder. Este problema da identificação era aquele do exército no qual era 
preciso encontrar os desertores, evitar as afiliações repetitivas, corrigir os estados fictícios apresentados pelos oficiais, conhecer os serviços e o valor de cada um, estabelecer com certeza o relatório dos desaparecidos e dos mortos. Era o problema dos hospitais onde era necessário reconhecer os doentes, deter os simuladores, seguir a evolução das doenças, verificar a eficácia dos medicamentos, determinar os casos análogos e os inícios de epidemias.

Era impossível que um médico, de qualquer memória superior que fosse dotado, administre os quadros de um enorme número de doenças (2 ou 30), se ele não tem diante de si um caderno, uma folha do diário de visita que lhe indique o estado de cada doente e o seguimento de seu tratamento [...] Algumas vezes, o doente que ele viu no dia anterior está morto, mudou de leito sem lhe avisar [...] Outras vezes, os doentes enganam o médico por ignorância ou por malícia; em outra acrescenta "a infeliz prática" de deitar dois ou mais doentes juntos ${ }^{11}$.

Era o problema dos estabelecimentos de ensino onde se tinha que caracterizar a aptidão de cada um, situar seu nível e suas capacidades, indicar a utilização eventual que se lhe podia fazer:

O registro serve para se recorrer a ele em momento propício, para conhecer os costumes das crianças, seus progressos na piedade, no catecismo; nos registos de suas permanências na escola, seus espíritos e julgamentos se encontrarão marcados desde sua recepção. Da mesma forma servirá para reconhecer as causas tanto da saída daqueles que foram detidos por indocilidade e maus exemplos quanto daqueles que sairão ou para morar fora, ou para deixar esta escola sem razão, nem sem dizer adeus, para ir a uma outra ${ }^{12}$.

Em resumo, seria preciso estabelecer uma escrita regulamentar, toda uma documentação individualizante.

Assim, começa a se elaborar um código físico, aquele da "sinalização". Após a grande leva de homens necessários para a Guerra dos

11 Du Laurens, Moyens de rendre les hôpitaux utiles (1787), p. 81-82.

12 M.I.D.B., Instruction méthodique pour lécole paroissiale (1669), p. 64. 
Trinta Anos, exige-se que cada companhia traga consigo suas relações com os nomes e sobrenomes, o lugar de nascimento e as marcas particulares de cada soldado ${ }^{13}$. No século XVIII, esta anotação das "marcas" começa a se tornar uma assinalação canônica segundo o tamanho, a corpulência, a forma do rosto, a cor dos cabelos e um pouco mais tarde, parece, aquela dos olhos. Descrição muito esquemática, mas que é importante para a interpretação geral que ela substitui às descrições "impressionistas" que se encontra facilmente na mesma época nos arquivos judiciários; uma certa percepção, canônica e administrativa, do corpo está em vias de se desenvolver, que servirá em seguida de ponto de partida para a antropologia física do século XIX. Forma-se igualmente os "código de sintomas": quando a prática hospitalar determinou a rotatividade dos médicos no leito dos doentes, quando ela tornou possível e sustentável a comparação dos casos de enfermaria a enfermaria, de hospital a hospital, e finalmente na segunda metade do século, de regiões a regiões, foi necessário encontrar um sistema para esquadrinhar regularmente os fenômenos patológicos: a comunicação, o acúmulo e a confrontação das experiências que lhes dependem. Daí, três processos marcaram a evolução do discurso médico no século XVIII: o hábito cada vez mais marcado de constituir observações escritas e sobretudo escritas diariamente; uma prática da descrição precisa, próxima dos fenômenos visíveis, cada vez menos engajados na teoria explicativa, cada vez mais voltada para a análise perceptiva final; e enfim, uma homogeneização do vocabulário, permitindo esquadrinhar e generalizar esses conteúdos de percepções. A aproximação crescente do olhar médico, a importância em reportar, por um lado ao menos, a esta necessidade da codificação e à disciplina que carregava consigo.

Disso, dois traços aparentemente contraditórios da medicina na segunda metade do século XVII: de um lado, afirmação do valor científico de um empirismo radical que teria por texto apenas os relatos de observação, recurso então a uma rigorosa modéstia clínica; por outro lado, recurso frequente ao modelo botânico para classificar as doenças, as espécies ao mesmo tempo estáveis, naturais, reconhecíveis a um

13 cf. Corvisier. 
certo número de traços canônicos que se pode decifrar entre os sintomas, como os caracteres lineanos das plantas. Esse recurso ao modelo botânico para o diagnóstico das doenças não responde ao cuidado único de dominar conceitualmente as desordens mórbidas da natureza; era também a emergência de uma medicina em vias de se constituir um sistema de documentação que o hospital tornou ao mesmo tempo possível e indispensável: encontrar uma língua comum, normalizar a percepção do corpo, constituir um campo coletivo de experiência. A imagem da doença-planta era talvez um princípio de pseudo-inteligibilidade; era também uma prescrição por uma linguagem.

Um "código" das performances ou das capacidades foi elaborado no ensino dos colégios e escolas técnicas. No início do século XVII, em um colégio como aquele de La Flèche, os professores trazem sobre cada aluno uma apreciação qualitativa simples (bom, mau, medíocre), segundo algumas rubricas (engenho, frequência, costumes, erudição), e essas apreciações, confidenciais, só podiam ser conhecidas por seus mestres ${ }^{14}$ : se está ainda numa relação pedagógica fechada sobre si mesma. Quatro ou cinco eixos principais de transformação no curso do século XVIII: esforços para instaurar categorias gerais permitindo caracterizar o conjunto de uma população escolar (os alunos das 12 escolas militares deveriam todos ser classificados segundo quatro rubricas: aptidões e disposições; aptidões sem disposição; disposição sem atitude; enfim nem aptidão e nem disposição); tentativa para quantificar o valor dos alunos (na escola de Ponts et Chaussées, o regulamento de 1775 estabelece um sistema de graus: cada aluno recebe um número proporcional ao nível de seus estudos anteriores, suas performances nas diferentes matérias ensinadas, ao trabalho prático que ele faz nas oficinas, a sua assiduidade geral ${ }^{15}$ ); importância crescente concedida à classificação ordinal dos alunos, uns em relação aos outros, como método para qualificar cada um; articulação desses procedimentos de classificação por provas regulares, comuns, canônicas, que dão um caráter público e administrativo para a qualificação assim obtida: na Escola de Ponts e

\footnotetext{
14 cf. Rochemonteix.

15 L'enseignement des sciences au XVIIIe siècle, p. 360-362.
} 
Chaussées, existe depois de 1775, 16 concursos por ano, três de matemática, três de arquitetura, um de corte de pedra, três de desenho, um de estilo, dois de escrita, um de edificação, um de nivelamento e um de fundação. E é a partir da classificação obtida nesses concursos que os alunos eram admitidos numa classe superior ${ }^{16}$.

$\mathrm{O}$ "código de condutas" permaneceu, para as categorias que se põe em jogo, muito rudimentar. Mas os procedimentos utilizados, os métodos de homogeneização dos dados tornam-se muito estritos. Em 1669, Batincour recomenda que as crianças encarregadas de visitar as famílias dos alunos ausentes ou demasiado indisciplinados façam aos pais uma série de questões: se é obediente, se briga com os irmãos e irmãs, se sai sem pedir autorização, se é ganancioso ou mentiroso, e acima de tudo "se ele reza a Deus, de manhã e à noite, muito devotamente". No início do século XVIII, Demia propõe dar a cada visitante um catálogo, dividido em colunas e em linhas: para cada linha, o nome do aluno visitado, e cada coluna correspondendo a uma questão precisa ( $1^{\underline{0}}$ se a criança reza a Deus; $2^{\underline{0}}$ se ele se ausentou da escola por sua culpa; $3^{\mathrm{o}}$ se é obediente; $4^{\mathrm{o}}$ preguiçoso; $5^{\mathrm{o}}$ ganancioso; $6^{\mathrm{o}}$ libertino; $7^{\circ}$ comete perjúrio; $8^{\circ}$ mentiroso; $9^{\circ}$ mau com seus irmãos e irmãs; $10^{\circ}$ "se frequenta más companhias sobretudo do sexo oposto"; $11^{\text {o }}$ "se diz palavras sujas"). Bastará então ao visitante marcar com um traço ou um ponto sobre as respostas positivas ou negativas que ele obtiver $^{17}$. Formação embrionária a partir de categorias tradicionais, uniformização de velhas práticas, regularização administrativa de algumas formas de controle e de qualificação; na verdade, todo esse "código" não traz consigo novidades tão imediatas. E, no entanto, um processo importante se desenha aí: o corpo, as aptidões, as capacidades, as condutas individuais começam a entrar nos procedimentos de escrita regrados que são todo um conjunto das formas de documentação e de instrumentos de poder. Para que esse código assegure uma captura sobre os indivíduos que seja permanente, é preciso toda uma técnica

${ }^{16}$ Da mesma forma, era previsto que a entrada na Escola militar de Paris seria concedida aos alunos das escolas militares de província, após sua classificação em um concurso comum, permanentemente aberto.

17 cf. Demia, Règlements pour les écoles de la ville de Lyon (1716), p. 39-40. 
de transcrição, de centralização, de circulação e de difusão dos documentos. Na prática judiciária, a marca era uma espécie de escrita somática, atrelada diretamente sobre o indivíduo por meio de uma marca corporal; por meio dela, o soberano imprimia um indivíduo com sua marca, dando meios de reconhecê-la. A disciplina fabrica instrumentos de controle muito mais sutis. Pode-se dizer que com ela, ainda que de maneira muito falha, começa a técnica do "dossiê" individual. Não mais o dossiê de uma "questão", de uma transação ou de um crime, mas aquele do indivíduo mesmo. Esse elemento móvel, retransmitido, repercutido, resumido, constitui como a versão administrativa da marca; uma visão sutil, manejável, de uma utilidade muito maior, posto que guardando sua referência precisa para um indivíduo singular, ela se destaca aí e põe à disposição instâncias que controlam. De um corpo real, sempre suscetível à fuga, a desaparecer, a se esconder, a reaparecer, a mudar de identidade, a prática documental traz uma sombra esquemática e constrangedora: são marcados traços úteis de um indivíduo, de maneira que possam servir ao mesmo tempo de regras de emprego possível, de esquemas para uma reparação, de elementos integráveis a dados futuros ou mais gerais. Formados a partir do indivíduo, mas descolados dele, circulam em torno dele, investindo-o desde cima, uma certa "identidade documental" se constitui: ela se dá como descrição do indivíduo, mas ela funciona também como instrumento para controlá-lo e o utilizar, e como prescrição a qual não se deve escapar.

Nesse suporte, que é ao mesmo tempo de observação e de poder, se define o que é um indivíduo, não seu estatuto ou seu nascimento, mas o que vale à pena, o que se lhe pode tirar, como se classifica em relação aos outros. O dossiê é o suporte de uma identidade disciplinar que é prévia ao indivíduo, que lhe é imposto em retorno como uma venda (descrição e qualificação) e que serve de regra em caso de sua eventual utilização. O Conselho da Escola Militar exigia, uma vez que se tratava de "formar os Reis sobre temas capazes de lhes servir de modo útil", que os alunos tivessem todos um dossiê aberto permanentemente para permitir um "conhecimento exato e detalhado das boas e más qualidades pessoais de cada um deles": foi então imposto 
aos capitães e tenentes de cada companhia formularem conjuntamente um relato dos alunos de sua companhia no qual eles detalharão seu julgamento ou observação sobre cada um deles e a classe na qual eles julgam que deveriam ser colocados, os professores adjuntos e mestres devem também aí formular [tal relatório] para os alunos de sua classe relativamente à sua dedicação e a seu progresso; os oficiais da Escola Militar endereçarão um igualmente para os exercícios militares e outras tarefas confiadas a seus cuidados. Todos esses relatórios devem ser reunidos no início de cada mês para que se possa notificar a partir daí a classificação dos alunos. Essa documentação individualizante supõe, não somente para ser estabelecida, mas para funcionar na instituição disciplinar, todo um sistema material de registro, de transcrições, de circulação das peças, de constituições de um arquivo global, todo um mecanismo de centralização e de totalização desse saber com seus efeitos específicos de controle. A identidade que determinam os aparelhos disciplinares é constrangedora na medida em que ela se forma e se fixa nos processos de centralização. Um estudo detalhado das técnicas de escrita disciplinares demanda sem dúvida a análise de diversos procedimentos.

Inicialmente aquela de "documentos de acompanhamento" que estão ligados ao indivíduo e constituem os indicadores de sua identidade: assim, esse "pequeno maço de papel" no qual tradicionalmente se marcam nos hospitais o nome e o sobrenome dos doentes, e que se lhes atam ao braço com "um pedaço de fio"18 (1620); assim, as folhas de identificação fixado aos leitos dos doentes, ou ainda esse sistema de duas cartas como é comum ao hospital Saint Sulpice:

o primeiro portando seu nome, o segundo indicando o dia de sua entrada; uma dessas cartas é atada ao pé do leito do doente, a outra às suas vestes, e quando a doença acaba, seja pela cura ou pela morte, essas duas cartas são distribuídas, uma à superiora, a outra ao médico que encerram sobre seu registro a notícia relativa a esse doente, constatando sua cura ou sua morte ${ }^{19}$.

\footnotetext{
18 Mémoire inséré dans la Délibération du Bureau de l'Hôtel-Dieu de Paris.

19 Journal de médecine, de chirurgie et de pharmacie (1785).
} 
Poder-se-ia citar igualmente o exemplo dessas "saídas" ou dessas "licenças" que alguns operários deviam, como os soldados, portar consigo em seus deslocamentos e que se generalizam no fim do século sob a forma da "caderneta" obrigatória: todos os operários deviam tê-las consigo até o momento da contratação quando eles depositavam nas mãos do mestre e para testemunhar seus empregos anteriores, seus deslocamentos e, frequentemente, a opinião de seus empregadores precedentes ${ }^{20}$. Assim, o corpo tem seu duplo escrito que lhe segue como sua sombra; ele o tem em seu pulso, em seu leito ou em suas vestes esse pequeno elemento documental, que desempenha o papel de indicador individual; é por causa dele que o corpo, morto ou vivo, destacado por um instante de uma multiplicidade confusa, torna-se, por todo um controle possível, individualizável.

Seria necessário também estudar os modos de retranscrição e de circulação dos documentos. Cada constituição disciplinar tem seu tipo de rede, suas vias de comunicação, e uma distribuição particular de pontos onde se acumula o saber para se difundir novamente como informação ou decisão. Em instituições tão restritas como as escolas elementares, essa rede é relativamente simples e curta; ela encerra os indivíduos no nível de seu comportamento o mais quotidiano: os alunos que estão ausentes, que não sabem suas lições ou que se mostram arrogantes são imediatamente "anotados" ou "marcados" no catálogo de bons ou maus pontos. Esses catálogos são submetidos ao mestre que a partir deles exige diariamente uma série de registros; na reunião do comitê das escolas, terá que dar um catálogo ou memória, $1^{\underline{0}}$ dentre os estudantes que foram mais inteligentes e que mais aproveitaram desde a oficina anterior, os mais pobres; $2^{\underline{0}}$ daqueles que estiveram ausentes frequentemente sem permissão e sobretudo no dia do catecismo; $3^{0}$ daqueles que foram suficientemente instruídos e que podem ser dispensados; $4^{\circ}$ daqueles que tendo feito alguma falta significativa que merecem ser corrigidos em plena oficina. Enfim, o mestre "remeterá ao secretário seu registro de nomes, sobrenomes, idade, profissão dos

${ }^{20}$ No século XIX foi proibido aos mestres de pôr nas cadernetas de seus operários suas apreciações pessoais. 
novatos vindos da última oficina" ${ }^{21}$. Nas escolas técnicas e sobretudo nas instituições militares, os circuitos de documentação são muito mais longos, posto que se trata de medir em escala nacional os efeitos desse novo tipo de formação, de verificar o bom uso das menções que foram atribuídas, e de decidir para cada aluno o que melhor o atinge. Quando se criou doze escolas militares na província, se nomeia um inspetor que deve circular entre cada uma delas; ele tem por tarefa redigir, para submetê-las ao ministro, cadernetas sobre todos os estabelecimentos visitados, descrevendo o funcionamento e avaliando a ordem. Ele deve também fazer relatórios sobre cada aluno em particular, indicar seu valor para as diferentes matérias estudadas ("objetos clássicos", matemáticas, línguas vivas, escrita, exercícios militares), definir sua conduta e seu caráter; enfim, ele deve seguir a carreira dos pensionistas egressos da escola, indicar seus empregos, em que corpos foram recrutados e se estão ainda a serviço do Rei ${ }^{22}$. Tudo em torno dos indivíduos, os dispositivos disciplinares tecem uma trama de escrita cada vez mais densa e extensa: esta permite ao mesmo tempo o exercício de um poder que é informado permanentemente até a fina poeira de existências e de condutas, e a formação de uma saber regrado, codificado, que tem sobre os indivíduos efeitos imediatos de coação.

A esta trama se acrescentam os meios para integrar esses dados individuais nas figuras de conjunto. As instituições disciplinares desenvolveram uma série de procedimentos que tem por função constituir campos de comparação e apreciação diferenciais enquanto mantém as singularidades identificáveis, e de produzir o surgimento dos efeitos globais, dos fenômenos de grupos e de populações. $\mathrm{O}$ arquivo disciplinar é ao mesmo tempo centralizador e totalizante, sobre um modo e com técnicas que são sem dúvida alguma moduladas sobre aquelas das grandes administrações, mas que são deslocadas e transformadas para poder se ajustar ao controle visado dos indivíduos. Exemplo: os grandes registros coletivos de notação, utilizados pelas Irmãs das Escolas Cristãs. Reagrupa-se o essencial do que é preciso saber sobre todas as

\footnotetext{
21 Demia.

22 C. De Monbey, Les Institutions d'éducation militaire.
} 
crianças inscritas; sob o nome de cada aluno são colocadas a data de sua entrada e seu nível nesse período a fim de "ver mais facilmente desde quando ele frequenta a escola e que progressos fez"; em seguida para cada matéria ensinada, uma cifra marca o estágio atingido na entrada escolar do ano em curso, depois o nível que sucessivamente se situa a cada mês, as boas e más notas obtidas nas composições gerais; uma coluna, enfim, é reservada para as observações particulares ${ }^{23}$. De sorte que é possível, ao exame desse grande registro, tirar recolher simultaneamente o nível atual de um indivíduo, sua evolução recente, o ritmo de seus progressos desde o início da escolarização, o nível geral dos alunos da escola, a velocidade média das aquisições, então a eficácia da pedagogia de cada mestre, a qualidade de uma escola comparada às outras. E entre as crianças, os casos excepcionais de atraso ou de rapidez: é através de procedimentos desse gênero que se pôde constituir controles globais da população escolar, uma elaboração concertada dos métodos pedagógicos, a localização dos fenômenos médios ou desviantes, e os esquemas de escolarização mais restritivos que se justifiquem pelo conhecimento da evolução "natural" ou "normal" da criança. A grande fabricação de arquivos propiciada pelos dispositivos disciplinares permitiu também tanto a observação dos traços de individualidade quanto a análise de variáveis coletivas. Desenha-se um campo de objetos definidos pela dupla polaridade indivíduo-população.

Nessa história da documentação disciplinar, os hospitais, com certeza, ocupam um lugar privilegiado. Do fim do século XVII ao começo do XIX se operou uma imensa mudança da documentação médica: essencialmente, ela se voltou em torno da formação de um arquivo hospitalar que era ao mesmo tempo da ordem do controle administrativo e da ordem da decifração patológica. Em cem anos, uma escrita médica é constituída, dotada de suportes numerosos mas coordenados; ela quadriculou segundo linhas entrecruzadas as observações e as práticas; ela constitui pelo investimento científico, econômico, político, da doença, um código novo que fixa, por volta do século XVIII, uma das condições de possibilidade da nova medicina, aquela de Bichat e dos clínicos.

23 J.-B. de La Salle, Conduite des écoles Chrétiennes (éd. 1728), p. 147-149. 
Às vésperas da Revolução, o equipamento e a regulamentação da escrita num hospital comportava em média os seguintes elementos ${ }^{24}$ : desde que um doente é admitido, após uma primeira visita pelo cirurgião de plantão, se o registra no diário de entrada, e se lhe põe no pulso um bilhete contendo a data de entrada, o número, o nome e sobrenome do paciente; dá também um outro cartão, assinado pelo cirurgião e que deve ser apresentado à enfermaria para onde é imediatamente conduzido. Na enfermaria, esse cartão é enviado a seguir à recepção para que se verifique se está de acordo com o diário de entrada da véspera. Todos os dias, o serviço deve comunicar ao controle financeiro "o movimento exato de todos os indivíduos existentes na casa"; todos os dias também um capelão toma a lista das crianças "para copiá-la em um diário mantido na sacristia". Em cada uma das enfermarias, há dois cadernos, destinados "a inscrever os medicamentos, as compressas e os regimes prescritos aos doentes"; um dos dois é mantido pelo aluno-cirurgião que deve tomar nota das decisões do médico; o outro é a transcrição do primeiro; ele contém todas as prescrições anteriores e está durante a visita nas mãos do médico, que pode assim acompanhar a evolução da doença e da cura. Esses cadernos têm seis colunas: na primeira, o número do leito; na segunda o nome do doente; depois os remédios em ordem; os alimentos da manhã e da tarde; enfim as sangrias, os curativos e as aplicações externas, as saídas dos doentes, as mudanças de enfermarias e os mortos. O médico assina seus cadernos ao fim de cada visita. Mas no curso dessas mesmas visitas, dois outros documentos são ainda estabelecidos: o enfermeiro ou enfermeira chefe anota em um cartão o regime prescrito para cada doente e o coloca na cabeceira do leito; um aluno-farmacêutico ou uma religiosa da farmácia escreve em um caderno as indicações concernentes os medicamentos ordenados; no fim da visita, esse caderno é confrontado com aquele mantido pelo cirurgião "a fim de evitar erros".

Após a visita, o aluno-cirurgião leva sucessivamente "em cada enfermaria de seu departamento, o relatório das decisões de alimentos prescritos, e formará a demanda de uns e de outros separadamente

24 Cf. por exemplo os regulamentos do Hospital Geral e do Grande Hotel Dieu de Lyon (1786), p. 29-34.

Rev. Filos., Aurora, Curitiba, v. 31, n. 52, p. 367-389, jan./abr. 2019 
por boletins assinados por ele"; ele carrega também o relatório "dos que fizeram sangria e outras aplicações que foram ordenadas em cada quarto e pelos intervalos de tempo indicados". Eis por que se constitui o registro médico da medicina hospitalar, a documentação que se estabelece dia após dia o mais próximo possível do doente e dos cuidados que se lhe dá. Mas há também os procedimentos de integração desses primeiros dados, todo um sistema de registro que permite as qualificações e as comparações. Todos os meses os médicos devem se "reunir para confrontar suas experiências, relatar os fatos essenciais de seu serviço no curso das semanas que se seguem" e "redigir por escrito suas observações que serão enviadas ao comitê da Assembleia". Para poder acumular os dados particulares em cada hospital, medir os fenômenos patológicos de uma população, assegurar uma vigilância médica de conjunto, o Conselho dos hospitais de Paris, em 1801, impôs o uso de oito tipos de documentos dos quais deu o procedimento preciso: registros interiores dos quartos, registro do serviço de entrada, fichas a endereçar semanalmente ao comitê central dos hospitais, fichas dos doentes que saíram, fichas dos doentes mortos, registros das admissões feitas pelo serviço central de admissão, registros mantidos pela administração central de cada hospital, registro indicando o movimento de população dos hospitais e hospícios de Paris ${ }^{25}$. O hospital disciplinado não é mais um "matadouro" mas um aparelho para observar, contar, medir, curar, experimentar, e ensinar também, produz sem cessar ao longo de toda sua atividade um imenso tecido documental que faz parte de seu trabalho quotidiano.

Toda a prática médica [se] encontra em um vasto procedimento de registro, que garante a constituição no saber médico de dois polos documentais, um clínico e rigorosamente individual, o outro coletivo e que faz aparecer fenômenos controláveis no nível das populações; uma medicina clínica e uma patologia estatística tornam-se ao mesmo tempo possíveis a partir desses procedimentos de escrita. Pelo mesmo fato se desenha uma grande inversão da relação entre escrita e saber sensível pela "destextualização" que já havia acompanhado a fundação das

25 [Referência ausente na publicação original (N.T.)]. 
ciências da natureza; a escrita-texto que urge conhecer, citar, comentar, a escrita-obra do mestre que detém o saber é senão substituída, ao menos largamente sucedida pela escrita-notação, a escrita-registro que permite a formação, o acúmulo e a verificação incessante do saber. Em pouco tempo o hospital, grande aparelho de documentação vai constituir o embasamento técnico para a refundação científica da medicina. E essa mudança, em uma ordem do conhecimento, já era pressentida pelos médicos que não eram capazes de prever aí a amplitude científica mas que decifravam a possibilidade na reorganização administrativa do hospital e na organização dessas técnicas de documentação. Escutemos du Laurens em 1765 vangloriar-se de um certo sistema de "folhas" que havia inventado:

É com a mais viva dor que ressinto de ver perecer tantas pessoas úteis que seria fácil curar e sobre a consideração de inutilidade de todos meus esforços para o bem que eu enfim concebi o feliz projeto de minhas folhas [...] Eu posso vos assegurar que só há este meio de tornar os hospitais úteis, de lhes conceder mais ordem e a maior exatidão. $\mathrm{O}$ médico presta verdadeiramente conta de sua conduta, mas ele teme quando tem as luzes que por direito se exige dele? Não se supõe que seja totalmente infalível [...] Não é ademais amplamente recompensado pela satisfação experimentada por assegurar melhor o estado de seus doentes, ao dar conta de suas declarações sempre presentes, ao se procurar um meio de justificação contra os inimigos ou os ignorantes, ao se esclarecer sobre sua arte, ao esclarecer os outros? Não tem ele o prazer exacerbado de servir em um canto do mundo a humanidade inteira, de dar lições úteis, de recebê-las, de levar a medicina à maior perfeição possível? Pela comparação com as revistas a que concordam essas folhas, os hospitais substituirão esses templos sagrados da antiguidade; e os médicos assim como os ministros de Deus renovarão os oráculos. Eu entrevejo toda a repugnância que alguns médicos que pouco merecem este título farão a este estabelecimento: acostumados a gozar de uma reputação comumente mais subjugada do que merecida, a ouvir decorar suas rotinas do bom nome da experiência, a ver mesmo seus usos errôneos fixados pelo hábito, eles temerão que essas folhas, fazendo cair a máscara, mostrem apenas o homem e dissipem o médico. Mas e o bem geral, o direito da humanidade, aqueles da ciência...? ${ }^{26}$

26 Carta de du Laurens à Poissonnier, 5 de novembro de 1765 ; cf. du Laurens, Moyens de rendre les hôpitaux utiles, p. 91-94. 
Seria preciso talvez reaproximar dois processos que são, grosso modo, contemporâneos e aparentemente inversos: uma alfabetização que, no século XVIII multiplica o número daqueles que são capazes de escrever, e a formação de dispositivos que tomam os indivíduos em processos incessantes de registro. Ensina-se a escrever, mas se investe pela escrita. Fabrica-se na escola sujeitos suscetíveis de dominar uma prática; e se utiliza essa prática para organizar sistemas de submissão. Duplo papel, então, dessa extensão da escrita: crescimento das capacidades de um lado, acirramento dos controles por outro. Entre esses dois processos, no entanto, não há relações inversas, mas ligações e apoio: a multiplicidade das instâncias de controle acentua a necessidade, ademais já bem grande, por indivíduos alfabetizados. E inversamente a fratura introduzida pela escolarização é largamente utilizada em todas as instituições de disciplina: a partir do momento que se sabe escrever, pode-se autorizar a vigiar, a apreciar, a anotar, a dar ordens; o manejo da escrita qualifica, ele marca um limiar hierárquico. Muito cedo, demandou-se que baixos oficiais do Exército sejam sempre escolhidos entre os soldados que sabiam escrever, podendo ter à mão os registros e fazer breves relatórios ${ }^{27}$. Os primeiros esboços de ensino mútuo que se deu em Batancour ou Demia articulam a aptidão de escrever e o exercício de um poder subordinado: aqueles que são capazes de ter cadernos e de tomar notas sobre a conduta dos outros recebem de fato o direito de controlá- $\operatorname{los}^{28}$. Não é seguro que nos ateliês de caridade dos anos 1789-90, nos quais é requisitado menos vigilantes sobre a escrita, ela hierarquize e confie poder. Além disso, por meio dela, se acrescenta toda uma rede documental que, partindo da base, converge ao se centralizar para as regiões mais altas da pirâmide hierárquica; as técnicas de registro e de transcrição reservam o saber àqueles que detêm o poder; elas permitem um acúmulo de saber sobre os indivíduos submetidos, que se tornam objetos, campos de análise, elementos a observar, a descrever, a codificar num sistema de informação; e elas permitem por

27 Praissac, nos Discours Militaires, já insiste sobre o fato que o sargento deve saber ler, escrever, contar. Sobre a educação dos soldados e dos oficiais no século XVIIII, cf. entre outros Beausobre: Commentaires sur les défenses des places (1757), t. 2, p. 298.

28 [Referência ausente na edição original (N.T.)]. 
outro lado um perpétuo reforço do poder posto que, acumulando ao seu redor os arquivos úteis, os ministros que decidem podem então fazer funcionar os indivíduos disciplinados como autômatos: a perfeição de sua obediência, as medidas do saber que se constituem sobre eles e acima deles. Como dizia Schauenbourg, "os comandantes de batalhão se persuadiram que o soldado só pode manobrar se ele é conduzido, atentando que ele está [...] inteiramente dispensado do conhecimento e da atividade dos oficiais que o comandam". A objetivação de uns por esses procedimentos documentais faz funcionar o poder dos outros; ou inversamente, o "mais-saber" que detêm aqueles e que os qualifica garante o assujeitamento dos primeiros. A escrita disciplinar joga o papel de permutador: ela é nas dissimetrias que introduz, no princípio de um processo entrecruzado de objetivação e assujeitamento, um sobre-poder e um sobre-saber que se convertem perpetuamente um no outro.

De uma forma geral, pode-se dizer que a utilização da escrita nos dispositivos de disciplina deu lugar, no curso do século XVIII, a um fenômeno importante: a objetivação documental do indivíduo. Dir-se-á que não era necessário aguardar tanto tempo, que as administrações fiscais ou judiciais tinham há muito tempo assegurado essa objetivação. Mas o próprio das técnicas disciplinares é dar os meios de se encarregar dos procedimentos de escrita dos indivíduos não como sujeitos de direito, titulares de bens, autores de infração, detentores de privilégios ou riquezas, mas como portadores de caracteres intrínsecos, de virtualidades ou de aptidões, de força ou de doenças, de habilidade, de saber-fazer. A disciplina faz aparecer ao mesmo tempo como objeto para um conhecimento e como alvo para um controle um indivíduo qualificado, e qualificado não por seu nascimento ou por seu status, mas pelo que pode fazer, por suas diferenças úteis, pelas séries em que se pode integrá-lo e fazê-lo funcionar. O procedimento de identificação permanente pelo qual a escrita disciplinar o submete se distingue do recenseamento administrativo ou de contabilidade econômica efetiva sobre uma população: ela é tão diferente dessas classificações por 
espécie que os naturalistas operam sobre os seres vivos; ela ata cada um à sua própria identidade caracterizada, e ela faz dessa singularidade, integrando-a a um aparelho documental, um dado que se pode descrever e uma armadilha pela qual o indivíduo não pode escapar.

Essa entrada do indivíduo quotidiano e qualificado em uma prática meticulosa de escrita e em um sistema regrado de arquivos, trás consigo duas transformações. Uma concerne à análise dos "casos" e a função que a escrita desempenha. Na prática cristã do "caso de consciência" só fazem parte do arquivo escrito as regras de resolução, os textos de referência, os esquemas ideais, os exemplos circunstanciados, podendo servir de modelo: mesmo que houvesse uma referência singular na realidade, o "caso" que se transcrevia era uma chave de análise para aplicações futuras; a questão mesma, com seus protagonistas e suas peripécias permaneciam da ordem oral. As disciplinas, ao contrário, começaram a estabelecer todo um arquivo que leva em conta os indivíduos cuidadosamente identificados, observados diariamente e descritos em sua realidade singular, ou, antes, no que é retido como tal por um certo número de códigos. Os casos deixados pelos diretores de consciência podem muito bem ser de extrema raridade, não se trata jamais apenas de uma semi-singularidade, oriunda de uma complicação da hipótese, do número de circunstâncias que se ajunta, da multiplicidade dos princípios contraditórios que se pode por em jogo: os casos de consciência registrados não são observações de penitentes, mas de regras de conduta para o diretor. A prática disciplinar, tal como se organiza no século XVIII, carrega a possibilidade de um registro e de uma descrição pela qual é o indivíduo mesmo que faz "caso" com sua vida, seu passado, sua conduta. Enquanto na direção de consciência, o "caso" é um esquema que pode eventualmente ser investido nos indivíduos, nos mecanismos disciplinares todo indivíduo é virtualmente um "caso" suscetível de ser descrito e analisado. Os anais da casuística são da ordem da jurisprudência, o registro disciplinar, mesmo sob sua forma mais frágil, carrega a possibilidade de uma "clínica", médica, psiquiátrica, psicológica, pedagógica, dos indivíduos.

Por meio dessa inversão epistemológica do "caso" está ligada uma outra transformação, mais política que aquela. Durante muito 
tempo, a individualidade qualquer - aquela de baixo e de todo mundo - permaneceu abaixo da linha de descrição. Ser visto, observado, relatado em detalhe, seguido dia após dia por uma escrita ininterrupta era um privilégio. A crônica de um homem, o relato de sua vida, sua historiografia redigida no fio de sua existência fazia parte dos rituais de sua potência. Ora, os procedimentos disciplinares retomam este relatório, abaixam o limiar da individualidade descritível e fazem dessa descrição um meio de controle e um método de dominação. Não mais monumento para uma memória futura, mas documento para uma eventual utilização. E essa descritibilidade nova é tão mais marcante quanto mais rigoroso é o enquadramento disciplinar: a criança, o doente, o louco, o condenado tornaram-se cada vez mais facilmente, a partir do século XVIII, e segundo uma inclinação que é aquela dos mecanismos de disciplina, o objeto de descrições individuais e de relatos biográficos. Essa escrita das existências reais não é mais um procedimento de heroicização: ela funciona como procedimento de objetivação e de assujeitamento. A vida cuidadosamente examinada dos doentes mentais ou outros delinquentes, evidencia, como a crônica dos reis, da epopeia dos bandidos famosos, uma certa função política da escrita, mas em uma totalmente outra técnica de poder.

Com os procedimentos de registro que o século XVIII utilizou, se dá início a um processo: uma prática ainda muito rudimentar da documentação individualizante está em vias de se tramar. Daí derivará em alguns decênios toda uma técnica da descrição, da biografia, da anamnese da observação quotidiana do interrogatório, do relato provocado. É desnecessário dizer que esta técnica utilizada muito cedo pela psiquiatria e pela criminologia foi, na história das ciências humanas, mais importante que o compasso de Fechner ou o reflexo psicogalvânico. Mais importante também que a noção de regressão ou a prática da hipnose. Não é preciso em todo caso inverter a ordem das coisas. Pôde-se, a partir de um certo momento, procurar no passado dos homens ou na totalidade de sua vida no que inocentar seu crime ou compreender sua loucura. Às questões secas das instâncias judiciárias ou administrativas - Quem és tu? Quais são teus direitos? Teus bens ou teus crimes? - todo um lote de novas curiosidades se acrescenta: Que tipo de homem és tu? 
Qual foi teu passado? Tua família, tua vizinhança? Como viveu, quais acontecimentos? Mas não é porque se havia por um lado admitido por postulado ou hipótese teórica que se encontraria aí um princípio de inteligibilidade. É antes de tudo porque uma técnica de observação, de registro e de controle fez a existência dos homens, ou ao menos alguns traços perceptíveis através de mecanismos disciplinares, um domínio para um conhecimento possível.

Recebido: 20/01/2019

Received: 01/20/2019

Aprovado: 22/02/2019

Approved: 02/22/2019 